\section{(C) \\ OPEN ACCESS}

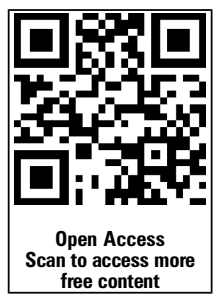

- Additional material is published online only. To view please visit the journal online (http://dx.doi.org/10.1136/bmjqs2014-003863)

For numbered affiliations see end of article.

\section{Correspondence to} Dr N Daneman, Division of Infectious Diseases, Department of Medicine, Sunnybrook Health Sciences Centre, University of Toronto, 2075 Bayview, G106, Toronto, ON M4N 3M5, Canada;

nick.daneman@sunnybrook.ca

Received 11 December 2014 Revised 1 April 2015

Accepted 8 April 2015

Published Online First

24 April 2015

\section{SLinked}

- http://dx.doi.org/10.1136/ bmjqs-2015-004344

\section{CrossMark}

To cite: Daneman $N$, Guttmann A, Wang X, et al. BMJ Qual Saf 2015;24: 435-443.

\title{
The association of hospital
} prevention processes and patient risk factors with the risk of Clostridium difficile infection: a population-based cohort study

\author{
N Daneman, ${ }^{1,2,3}$ A Guttmann, ${ }^{1,3,4,5} \times$ Wang $^{1}{ }^{1} \times \mathrm{Ma}{ }^{1} \mathrm{D}$ Gibson, ${ }^{6}$ \\ TA Stukel ${ }^{1,3}$
}

\begin{abstract}
Background Clostridium difficile is the most common cause of healthcare-acquired infection; the real-world impacts of some proposed $C$. difficile prevention processes are unknown. Methods We conducted a population-based retrospective cohort study of all patients

Conclusions In the largest study to date, selected hospital prevention strategies were not associated with a statistically significant reduction in patients' risk of $C$. difficile infection. These prevention strategies have either limited effectiveness or were ineffectively implemented during the study period.
\end{abstract} admitted to acute care hospitals between April 2011 and March 2012 in Ontario, Canada. Hospital prevention practices were determined by survey of infection control programmes; responses were linked to patient-level risk factors and $C$. difficile outcomes in Ontario administrative databases. Multivariable generalised estimating equation (GEE) regression models were used to assess the impact of selected understudied hospital prevention processes on the patient-level risk of $C$. difficile infection, accounting for patient risk factors, baseline $C$. difficile rates and structural hospital characteristics.

Results C. difficile infections complicated 2341 of 653896 admissions (3.6 per 1000 admissions). Implementation of the selected $C$. difficile prevention practices was variable across the 159 hospitals with isolation of all patients at onset of diarrhoea reported by 43 (27\%), auditing of antibiotic stewardship compliance by $26(16 \%)$, auditing of cleaning practices by 115 (72\%), on-site diagnostic testing by $74(47 \%)$, vancomycin as first-line treatment by 24 (15\%) and reporting rates to senior leadership by 52 (33\%). None of these processes were associated with a significantly reduced risk of $C$. difficile after adjustment for baseline $C$. difficile rates, structural hospital characteristics and patient-level factors. Patient-level factors were strongly associated with $C$. difficile risk, including age, comorbidities, non-elective and medical admissions.

\section{BACKGROUND}

Clostridium difficile is the most burdensome gastrointestinal infection in developed countries and among the top 10 infectious causes of death. ${ }^{1}$ The morbidity and mortality of C. difficile is especially concerning because this infection is usually acquired in the process of care provision, particularly in acute care hospitals, where our sickest and most vulnerable patients receive treatment. C. difficile is a crucial patient safety issue, as it is the single most common cause of healthcare-associated infections. ${ }^{2}$

The burden of hospital-acquired C. difficile infections, coupled with the perceived preventability of these infections, prompted the Ontario Ministry of Health and Long-Term Care (MOHLTC) to select C. difficile rates as the first hospital patient safety indicator to be subject to mandatory public reporting in September 2008. Our group determined that this public reporting campaign was associated with a rapid $26 \%$ reduction in $C$. difficile cases or nearly 2000 cases prevented per year. ${ }^{3}$ However, we lacked information on hospital-specific $C$. difficile prevention practices, and so, we could not illuminate the active ingredients in C. difficileprevention efforts, nor explain the source of variability in rates of $C$. difficile across 
hospitals. Just as the hospital-level factors influencing C. difficile risk have not been well studied, information on patient-level risk factors for C. difficile infection is derived primarily from single-centre studies. Understanding the broad drivers of $C$. difficile risk is growing ever more importantly in an era of hospital quality indicators, mandatory public reporting ${ }^{4}$ and strict financial disincentives such as non-payment policies for preventable infections. ${ }^{5}$

Therefore, the primary goal of this populationbased, Ontario-wide, retrospective cohort study was to examine the incremental influence of selected understudied hospital C. difficile prevention strategies on patients' risk of acquiring C. difficile infection during their hospital stay, after accounting for baseline C. difficile rates, structural hospital characteristics and patient risk factors; the secondary goal was to elucidate which patient groups are most at risk of this infection.

\section{METHODS}

\section{General study design}

We conducted a retrospective cohort study of patients admitted to acute care hospitals in Ontario, Canada's largest and most populous province (13 million residents), between 1 April 2011 and 31 March 2012. Through multivariable generalised estimating equation (GEE) binary regression analysis, we assessed the impact of patient risk factors, baseline C. difficile rates, structural hospital characteristics and hospital $C$. difficile prevention processes on the patient-level risk of $C$. difficile infection.

\section{Hospital selection criteria}

The study included all acute care hospitals in Ontario, which had been surveyed by the Ontario MOHLTC and Public Health Ontario (PHO) regarding C. difficile infection control processes.

\section{Patient selection criteria}

We included all first admissions for patients $>1$ year of age to these acute care hospitals in Ontario during the study year. We restricted to the first hospital admission for each patient. We also excluded admissions, which occurred within 8 weeks of discharge related to a C. difficile hospitalisation, so as to count only incident cases rather than relapses.

\section{Administrative data sources}

The study used population-based administrative databases derived from Ontario's universal single-payer healthcare system. At the Institute for Clinical Evaluative Sciences (ICES), these well-validated databases are linked through encoded healthcare numbers, and have been used extensively in prior research, ${ }^{6-8}$ including studies of C. difficile infection. ${ }^{3}{ }^{9}$ Hospital admissions and C. difficile events were identified from the Canadian Institute for Health Information
Discharge Abstract Database, which describes all hospitalisation events in the province. Multiple databases contributed to measurement of patient-level risk factors, including this hospital database and provincial databases recording same-day surgeries, emergency department visits, ${ }^{10}$ home-care treatments, long-term care residence, ${ }^{11}$ physician billing claims ${ }^{12}$ and vital statistics.

\section{Ontario hospital corporation survey of $C$. difficile prevention processes}

In February 2011, the Ontario MOHLTC surveyed Ontario hospital corporations to examine the current state of C. difficile prevention practices and approaches. The mandatory survey, developed by the MOHLTC in conjunction with PHO, was completed by an infection control practitioner or senior manager knowledgeable about the facility's infection prevention and control activities. The survey was administered at the level of hospital corporations, given that most infection control programmes are distributed across and responsible for all sites of a hospital corporation. However, our analyses map the responses to each individual hospital within a corporation. The Sunnybrook Research Ethics Board, ICES and the MOHLTC approved linkage of the de-identified hospital survey responses to the administrative databases.

\section{Outcome measure}

The primary outcome was the diagnosis of C. difficile infection, as defined by International Classification of Diseases, 10th edition (ICD-10) code A047 in the hospital database. This outcome was measured at the patient level. We did not count C. difficile cases, which were labelled as preadmission diagnoses. Our previous work in Ontario has confirmed that hospital C. difficile rates measured in these databases are strongly correlated with rates reported by active infection control surveillance programmes as part of mandatory hospital reporting (Pearson's correlation coefficient 0.92 ). ${ }^{3}$ Two patient-level validation studies in the USA have also confirmed that ICD codes are highly specific (>99\%) for the diagnosis of C. difficile infection. ${ }^{13}{ }^{14}$ In a sensitivity analysis, we limited $C$. difficile outcome events to those labelled as type 2 (postadmission) diagnoses. However, we did not limit to type 2 diagnoses for our main analysis given that the majority of $C$. difficile infections are hospital acquired, and limiting to type 2 cases likely undercounts hospital-acquired cases since less than half of the cases are designated as type $2 .^{3}$

\section{Patient risk factors}

A 1 year look-back window prior to admission was used to capture extensive patient-level factors that could potentially impact the risk of $C$. difficile infection. Demographic factors included age group and sex; comorbidity was measured through the presence 
or absence of each of the 16 individual comorbidities of interest; type of admission was categorised as elective versus non-elective and separately as belonging to medical, surgical, obstetrical or other services. The calendar month of admission was recorded given that C. difficile infections are seasonal. ${ }^{15}$ We identified recent healthcare exposure in the 8 weeks preceding admission, including any hospital admission, emergency department visit, same-day surgery procedure, residence in a long-term care facility, receipt of outpatient haemodialysis, outpatient chemotherapy or home-care treatment. ${ }^{16}$ Although antibiotic treatment data are unavailable for inpatients and non-elderly outpatients, we determined whether the most responsible diagnosis for the current admission was a bacterial infection that would typically warrant antibiotic treatment. We also determined whether a bacterial infection had been diagnosed in the 8 weeks prior to admission. ${ }^{1}$

\section{Structural hospital characteristics and baseline C. difficile rates}

We measured baseline C. difficile rates in 2007 since current rates can be influenced by previous rates within an institution. We chose 2007 as a baseline year since mandatory public reporting was introduced in Ontario in 2008 and would be expected to have stimulated implementation of new hospital prevention processes. ${ }^{3}$ We also measured some non-modifiable structural hospital characteristics in the administrative databases, including hospital type, since C. difficile rates are typically higher in academic/teaching hospitals and larger community hospitals and could confound the association between prevention practices and C. difficile rates. $^{3} 17$ Academic/teaching hospitals were defined based on full affiliation with the Council of Academic Hospitals of Ontario. Non-academic hospitals were subcategorised based on numbers of beds and yearly admissions as large, medium and small community hospitals. Using survey data, we also categorised the proportion of single-bedded rooms as $<25 \%$ of hospital beds, $25 \%-35 \%$ of beds or $>35 \%$ of beds. ${ }^{18}$

\section{Hospital processes of care}

Hospital processes of care were identified from survey responses. The primary predictors of interest in this study were prespecified to include one variable from each survey domain: infection control policies to decrease transmission, antimicrobial stewardship, environmental cleaning, diagnostic testing, treatment and leadership/culture (online supplementary table S1). Two investigators, one hospitalist and one infectious diseases specialist selected one most relevant question item from each domain based on (a) the potential to result in reduced $C$. difficile rates, (b) the likelihood that the respondents would be able to accurately gauge that hospital characteristic and (c) the expectation of variability in implementation across Ontario hospitals at the time of the survey. For example, we did not select use of contact precautions for $\mathrm{C}$. difficile as a predictor because contact precautions are used for $C$. difficile in $100 \%$ of hospitals. ${ }^{17}$ Instead, the infection control policy of interest was whether contact precautions are implemented immediately at the onset of diarrhoea versus at any other time point (only after patients meet qualified definitions of diarrhoea, only after physicians' order, only after advice of infection control professional or only after a positive confirmatory test result). The antimicrobial stewardship item of interest was whether the hospital reported auditing compliance of staff with antibiotic stewardship policies; similarly, the environmental cleaning predictor of interest was whether there was a system of auditing compliance of housekeeping staff with policies. With respect to C. difficile diagnosis, we categorised hospitals by whether testing was available on-site versus sending to off-site hospital laboratories or the public health laboratory, given that these could potentially be associated with a delayed turnaround time. We adjusted for C. difficile testing method given that use of sensitive PCR methods have been associated with higher detection rates of C. difficile. ${ }^{19}$ With respect to C. difficile treatment, we categorised hospitals based on reported use of vancomycin versus metronidazole as first-line treatment; even though vancomycin is not necessarily recommended as first-line treatment in all current guidelines, it has the potential to lead to higher and faster diarrhoea resolution rates ${ }^{20}$ and potentially decreased C. difficile shedding and transmission. Lastly, as a measure of leadership and culture, we categorised hospitals as to whether their infection control programme reported C. difficile rates to the chief executive officer or hospital board versus lower levels of the administration hierarchy.

\section{Statistical analysis}

In descriptive analyses, we calculated the prevalence of each of the six prevention processes across Ontario hospitals overall, and stratified by hospital type. The outcome was the diagnosis of C. difficile infection measured at the patient level. We used multivariable binary GEE regression models to assess the impact of hospital survey factors on the patient-level risk of $C$. difficile infection, accounting for baseline C. difficile rates, structural hospital characteristics and patient characteristics. All predictor variables were included in this model because we aimed to examine the impact of hospital prevention methods after accounting for all of these other prespecified patient-level and hospital-level characteristics; variable reduction was not required given the large number of outcome events. We incorporated GEE to account for clustering of patients within hospitals. ${ }^{21}$ Analyses were performed using SAS statistical software V.9.3 (SAS, Cary, North Carolina, USA) and STATA. Confidentiality was maintained via encrypted health card numbers and strict safeguarding protocols at ICES. 


\section{RESULTS}

\section{Baseline patient characteristics}

During the study year, 653896 unique patients $>1$ years old were admitted to acute care hospital beds in Ontario. The most common categories of admission were medical (268 852, 41\%), surgical (218 646, 33\%) and obstetrical (133 983, 21\%), and most admissions were designated as non-elective (399 958, 61\%). More than one-third (248 889, $38 \%$ ) of patients were elderly, $\geq 65$ years old, and nearly two-thirds (404 980, 62\%) were women.

The most common comorbid medical diagnoses were diabetes mellitus (14\%), cancer (8.6\%), chronic obstructive pulmonary disease $(6.0 \%)$ and congestive heart failure (4.8\%). Even though the population was restricted to the first hospital admission per patient in the study year, recent healthcare exposure was common in the 8 weeks prior to admission, with as many as 195782 (30\%) having been seen in the emergency room and 80287 (12\%) having received home care.

\section{Baseline hospital characteristics}

The 653896 unique patient admissions amounted to a total of 3798409 patient days in hospital, which were distributed across 124 hospital corporations. All hospital corporations $(124 / 124,100 \%)$ responded to the mandatory survey, thereby providing information for 159 distinct hospital sites. These 159 facilities included 17 academic/teaching hospitals, 22 large community hospitals, 23 medium community hospitals and 97 small community hospitals.

There was substantial heterogeneity in the implementation of the six specific $C$. difficile prevention processes (table 1), with 17 (11\%) of the hospitals reporting implementation of none of these procedures, 37 (23\%) reporting one, 46 (29\%) reporting two, $37(23 \%)$ reporting three, $17(11 \%)$ reporting four, $4(3 \%)$ reporting five and only $1(0.6 \%)$ reporting all six. Full responses to other survey items are listed in online supplementary table S1.

\section{Risk of C. difficile infection during acute care hospitalisation in Ontario}

Overall, 2341 of 653896 admissions were associated with C. difficile infections for a rate of 3.6 per 1000 admissions or 6.2 per 10000 patient days. Severe outcomes were more common among patient admissions with $C$. difficile infection as compared with admissions without $C$. difficile, including intensive care unit admissions $(23.8 \%$ vs $6.5 \%, \mathrm{p}<0.001)$, colectomy $(4.4 \%$ vs $1.6 \%, \mathrm{p}<0.001)$ and death within 30 days (23.9\% vs $4.8 \%, \mathrm{p}<0.001)$.

\section{Patient risk factors for $\mathrm{C}$. difficile infection}

As compared with patients without $C$. difficile infection, those with this infection were more likely to be older, admitted non-electively and to medical services (table 2). Those with C. difficile also had significantly higher rates of comorbidities, greater exposure to healthcare settings in the previous 8 weeks and more frequent confirmed diagnoses of bacterial infection in the preceding 8 weeks or as the most responsible diagnosis for the current admission (table 2). Multivariable logistic regression analysis confirmed that age, comorbidities and medical non-elective admissions were strongly predictive of increased risk of $C$. difficile infection (table 3 ). These findings were consistent in a sensitivity analysis limited to C. difficile cases labelled as postadmission diagnoses (data not shown).

\section{Hospital risk factors for $\mathrm{C}$. difficile infection}

The prevalence of hospital structural characteristics and prevention processes among patients with and without C. difficile infection are displayed in table 2 . Multivariable adjustment accounting for patient and hospital factors confirmed an increased risk of $C$. difficile in hospital types other than small community hospitals (table 3). Use of PCR methods was associated with significantly higher risk of C. difficile (adjusted OR 1.40, 95\% CI 1.03 to $1.91, \mathrm{p}=0.03$ ) (table 3). However, none of the six prespecified selected hospital prevention processes were associated with a significantly lower risk of $C$. difficile (table 3 ). These findings were consistent in a sensitivity analysis limited to $C$. difficile cases labelled as postadmission (type 2) diagnoses (data not shown).

\section{DISCUSSION}

Our analysis of more than 650000 patients admitted to Ontario's 159 acute care hospitals has documented wide variability in reported implementation of the selected understudied $C$. difficile infection-prevention processes, and found that none of these hospital processes were strongly associated with a patient's risk of acquiring $C$. difficile. Our findings confirm that patient-level risk factors are crucial drivers of C. difficile infection. C. difficile risk is most strongly associated with older age, non-elective and medical admissions and specific medical comorbidities, including inflammatory bowel disease, peptic ulcer disease, liver disease, immunocompromise, peripheral vascular disease, congestive heart failure, hemiparesis/paraplegia and dementia.

Our study is strengthened by a population-based assessment of $C$. difficile risk in a large jurisdiction. It is the largest study of patient-level and hospital-level risk factors, with rare access to both complete patientlevel data for 650000 patients and complete hospitallevel survey data for 159 hospitals. Nevertheless, an observational study using retrospective administrative data may be subject to some important limitations. The presence of $C$. difficile may have been misclassified in some cases, but the literature suggests very high specificity of the ICD diagnostic code for $C$. 
Table 1 Clostridium difficile prevention processes across Ontario acute care hospitals

\begin{tabular}{|c|c|c|c|c|c|c|}
\hline $\begin{array}{l}\text { General } \\
\text { domain }\end{array}$ & $\begin{array}{l}\text { Specific } \\
\text { item }\end{array}$ & $\begin{array}{l}\text { All hospitals } \\
N=159\end{array}$ & $\begin{array}{l}\text { Academic/ } \\
\text { teaching } \\
\mathrm{N}=17\end{array}$ & $\begin{array}{l}\text { Large } \\
\text { community } \\
\mathrm{N}=22\end{array}$ & $\begin{array}{l}\text { Medium } \\
\text { community } \\
\mathrm{N}=23\end{array}$ & $\begin{array}{l}\text { Small } \\
\text { community } \\
\mathrm{N}=97\end{array}$ \\
\hline Infection control & Isolation at onset of diarrhoea & $43(27 \%)$ & $10(59 \%)$ & $6(27 \%)$ & $3(13 \%)$ & $24(25 \%)$ \\
\hline Antibiotic stewardship & Audit of antibiotic use & $26(16 \%)$ & $6(35 \%)$ & $6(27 \%)$ & $4(17 \%)$ & $10(10 \%)$ \\
\hline Environmental cleaning & Audit of cleaning practices & $115(72 \%)$ & $15(88 \%)$ & $20(91 \%)$ & $18(78 \%)$ & $62(64 \%)$ \\
\hline Diagnosis & On-site diagnostic testing & $74(47 \%)$ & $11(65 \%)$ & $15(68 \%)$ & $13(57 \%)$ & $35(36 \%)$ \\
\hline Treatment & Vancomycin as first-line treatment & $24(15 \%)$ & $4(24 \%)$ & $0(0 \%)$ & $2(9 \%)$ & $18(19 \%)$ \\
\hline Leadership & Reporting to senior leadership & $52(33 \%)$ & $6(35 \%)$ & $6(27 \%)$ & $5(22 \%)$ & $35(36 \%)$ \\
\hline
\end{tabular}

difficile, ${ }^{13} 14$ and we have also demonstrated high correlation of ICD-based C. difficile rates with those measured by Ontario hospital infection-surveillance programmes. ${ }^{3}$ The survey results were self-reported by hospital infection control programmes, and so, there could have been misclassification of exposure variables related to variable stringency of interpretation regarding the implementation of prevention processes across the different hospitals. Although we selected processes that we felt were easier to gauge in comparison to other processes, even these items were open to some subjectivity in interpretation. The dates of implementation of hospital processes were not collected in the MOHLTC survey, and so, it is possible that high C. difficile rates may have driven process implementation, thereby obscuring any benefit of these processes. We sought to account for this by adjusting for 2007 hospital C. difficile rates (the year prior to mandatory public reporting), but this approach may be imperfect. Antibiotics are the most important risk factor for C. difficile, and inpatient drug use is not available in the Ontario administrative databases; therefore, our results may have been subject to indication bias. However, we designed our model to be based on risk factors present and definable on hospital admission, and so, a diagnosis of bacterial infection served as an appropriate surrogate. ${ }^{22}$ Lastly, strain type was not available for a study of this size; so, we cannot determine whether there were hospital variations in the prevalence of more virulent $C$. difficile strains, such as the epidemic NAP1/ribotype 027 strain.

The patient risk factors identified in our populationbased study are consistent with those in previous single-centre studies. ${ }^{23-27}$ Increased age is among the most well established predictors of $C$. difficile risk, and could relate to increased frailty, immune senescence and high rates of hospital contact and antibiotic exposure, but may also be driven by an age-related reduction in the protective diversity of the gut microbiome. ${ }^{28}$ Multiple aggregate scores of comorbidity have been associated with C. difficile risk, ${ }^{24} 2527$ and we have more specifically delineated the types of individual comorbidities most strongly linked with C. difficile. The most important comorbidities appear to be those associated with bowel inflammation (inflammatory bowel disease), need for gastric acid suppression (peptic ulcer disease), decreased intestinal blood supply (congestive heart failure, peripheral vascular disease), immunocompromise or greater likelihood of being confined to bed (hemiparesis/paraplegia, dementia). Our model is limited to patient-level characteristics definable on admission to hospital, and therefore has the potential to identify high-risk patients for targeted surveillance and prevention efforts. Our model is derived from population-wide data sources, and so has the potential to improve patient-level risk adjustment to improve inter-hospital comparisons and performance measurement.

Although C. difficile prevention guidelines have been widely published and endorsed by professional societies ${ }^{29}$ very few previous studies have explicitly examined the impact of hospital-level factors on $C$. difficile risk for patients. ${ }^{30} 31 \mathrm{~A}$ population-based study in Quebec examined hospital factors associated with increased $C$. difficile incidence during preepidemic and epidemic periods in that province. This study was large, but the investigators did not have information on hospital-specific C. difficile prevention processes; so, they were only able to examine structural hospital characteristics such as geographical location, size and academic category. ${ }^{30} \mathrm{~A}$ retrospective study in the Netherlands detected an association of hospital-level class-specific antibiotic use, isolation discontinuation policy, disinfection solution and frequency and a few other infection prevention policies with aggregate hospital-level C. difficile rates. $^{31}$ However, their study was conducted during a timelimited outbreak, included only 23 voluntarily participating hospitals from a total of 98 in the country and could not account for patient-level risk factors. ${ }^{31}$

We studied putative prevention factors across six domains of hospital C. difficile prevention, but none were associated with a significant reduction in patient risk of C. difficile infection. A meaningful impact of these prevention processes could have been missed in our study if, for example, higher rates of infection have also prompted some hospitals to be more likely to implement these processes. It is also possible that these self-reported C. difficile infection prevention 
Table 2 Baseline characteristics among patient admissions with versus without Clostridium difficile infection

\begin{tabular}{lll}
\hline No C. difficile & C. difficile \\
$(\mathrm{n}=651555)$ & $(\mathrm{n}=2341)$ \\
$\mathrm{N}(\%)$ & $\mathrm{N}(\%)$ \\
\hline
\end{tabular}

Patient characteristic
Age group (years)
$1-10$
$11-17$
$18-44$
$45-64$
$65-74$
$75-84$
$\geq 85$

Female sex

Admission type

Medical

Surgical

Obstetrical or other

Elective admission

Infection as most responsible diagnosis

Previous diagnoses

\begin{tabular}{lrc} 
Myocardial infarction & $27173(4.2 \%)$ & $155(6.6 \%)$ \\
Congestive heart failure & $30741(4.7 \%)$ & $346(14.8 \%)$ \\
Peripheral vascular disease & $9782(1.5 \%)$ & $102(4.4 \%)$ \\
Cerebrovascular disease & $20431(3.1 \%)$ & $144(6.2 \%)$ \\
Dementia & $20015(3.1 \%)$ & $241(10.3 \%)$ \\
Chronic obstructive pulmonary & $38879(6.0 \%)$ & $286(12.2 \%)$ \\
disease & & \\
Rheumatological disease & $3951(0.6 \%)$ & $35(1.5 \%)$ \\
Peptic ulcer disease & $4450(0.7 \%)$ & $57(2.4 \%)$ \\
Diabetes mellitus & $91592(14.1 \%)$ & $572(24.4 \%)$ \\
Hemiparesis/paraplegia & $55749(8.6 \%)$ & $294(12.6 \%)$ \\
Renal disease & $7290(1.1 \%)$ & $88(3.8 \%)$ \\
Malignancy & $3955(0.6 \%)$ & $48(2.1 \%)$ \\
Liver disease & $15616(2.4 \%)$ & $200(8.5 \%)$ \\
Inflammatory bowel disease & $4913(0.8 \%)$ & $43(1.8 \%)$ \\
HIV or other immunocompromise & $4934(0.8 \%)$ & $66(2.8 \%)$ \\
Healthcare exposure in preceding 8 weeks & & \\
Hospital admission* & $9571(1.5 \%)$ & $139(5.9 \%)$ \\
Emergency department visit & $194621(29.9 \%)$ & $1161(49.6 \%)$ \\
Past gastrointestinal procedure & $17499(2.7 \%)$ & $104(4.4 \%)$ \\
Same-day surgery procedure & $36206(5.6 \%)$ & $152(6.5 \%)$ \\
Nursing home stay & $1851(0.3 \%)$ & $27(1.2 \%)$ \\
Haemodialysis & $4192(0.6 \%)$ & $53(2.3 \%)$ \\
Chemotherapy & $11060(1.7 \%)$ & $73(3.1 \%)$ \\
Homecare treatment & $79564(12.2 \%)$ & $723(30.9 \%)$ \\
Recent diagnosis of infection & $196828(30.2 \%)$ & $1190(50.8 \%)$ \\
Calendar month of admission & & \\
January & $49975(7.7 \%)$ & $164(7.0 \%)$ \\
February & $47838(7.3 \%)$ & $169(7.2 \%)$ \\
March & $50275(7.7 \%)$ & $156(6.7 \%)$ \\
April & $66767(10.2 \%)$ & $353(15.1 \%)$ \\
May & $63047(9.7 \%)$ & $256(10.9 \%)$ \\
\hline & & Continued \\
& &
\end{tabular}

Table 2 Continued

\begin{tabular}{|c|c|c|}
\hline & $\begin{array}{l}\text { No } C \text {. difficile } \\
(\mathrm{n}=651555) \\
\mathrm{N}(\%)\end{array}$ & $\begin{array}{l}\text { C. difficile } \\
(\mathrm{n}=2341) \\
\mathrm{N}(\%)\end{array}$ \\
\hline June & $59250(9.1 \%)$ & $231(9.9 \%)$ \\
\hline July & $54464(8.4 \%)$ & $198(8.5 \%)$ \\
\hline August & $52474(8.1 \%)$ & $204(8.7 \%)$ \\
\hline September & $52995(8.1 \%)$ & $138(5.9 \%)$ \\
\hline October & $52780(8.1 \%)$ & $164(7.0 \%)$ \\
\hline November & $51594(7.9 \%)$ & $157(6.7 \%)$ \\
\hline December & $50096(7.7 \%)$ & $151(6.5 \%)$ \\
\hline \multicolumn{3}{|l|}{ Hospital characteristic } \\
\hline \multicolumn{3}{|l|}{ Hospital type } \\
\hline Academic/teaching & $207942(31.9 \%)$ & $746(31.9 \%)$ \\
\hline Large community & $248377(38.1 \%)$ & $869(37.1 \%)$ \\
\hline Medium community & $118463(18.2 \%)$ & $497(21.2 \%)$ \\
\hline Small community & $76773(11.8 \%)$ & $229(9.8 \%)$ \\
\hline \multicolumn{3}{|c|}{ Proportion of beds in single-bed rooms } \\
\hline$<25 \%$ & $193195(29.7 \%)$ & $638(27.3 \%)$ \\
\hline $25 \%-35 \%$ & $81843(12.6 \%)$ & $324(13.8 \%)$ \\
\hline$>35 \%$ & $245677(37.7 \%)$ & $890(38.0 \%)$ \\
\hline Not available & $130840(20.1 \%)$ & $489(20.9 \%)$ \\
\hline \multicolumn{3}{|l|}{ Hospital processes of care } \\
\hline $\begin{array}{l}\text { Immediate isolation for patients } \\
\text { with diarrhoea }\end{array}$ & $222265(34.1 \%)$ & $735(31.4 \%)$ \\
\hline $\begin{array}{l}\text { Audit of compliance for antibiotic } \\
\text { stewardship }\end{array}$ & $195921(30.1 \%)$ & $748(32.0 \%)$ \\
\hline $\begin{array}{l}\text { Audit of compliance of } \\
\text { environmental cleaning }\end{array}$ & $562104(86.3 \%)$ & $2102(89.8 \%)$ \\
\hline $\begin{array}{l}\text { Reporting to CEO or hospital } \\
\text { board }\end{array}$ & $217603(33.4 \%)$ & $739(31.6 \%)$ \\
\hline $\begin{array}{l}\text { On-site C. difficile diagnostic } \\
\text { testing }\end{array}$ & $428694(65.8 \%)$ & $1482(63.3 \%)$ \\
\hline $\begin{array}{l}\text { Use of vancomycin as first-line } \\
\text { treatment }\end{array}$ & $73284(11.2 \%)$ & $288(12.3 \%)$ \\
\hline
\end{tabular}

practices do not adequately reflect actual C. difficile practices, or that there may have been variability across institutions in what survey respondents considered to be adequate implementation of a particular process. For example, a meta-analysis suggests that antimicrobial stewardship can reduce $C$. difficile incidence by $50 \%{ }^{32}$; the lack of association between antibiotic stewardship and reduced C. difficile infections in this study may reflect low rates of stewardship auditing (reported by only 16\% of hospitals) and that many of these auditing efforts or stewardship programmes themselves were likely still early in their evolution or implementation at the time of this study. ${ }^{33}$

Our findings, though, do raise the possibility that some current best practices may be suboptimal approaches to preventing this challenging infection. Most prevention practices focus on detecting and isolating symptomatic patients with $C$. difficile diarrhoea and 
Table 3 Multivariable binary generalised estimating equations (GEE) regression modelling the impact of patient and hospital-level predictors on the patient-level risk of Clostridium difficile infection

\begin{tabular}{|c|c|c|c|}
\hline & Adjusted OR & $95 \% \mathrm{Cl}$ & p Value \\
\hline \multicolumn{4}{|l|}{ Patient characteristic } \\
\hline \multicolumn{4}{|l|}{ Age group (years) } \\
\hline $1-10$ & 0.15 & 0.07 to 0.31 & $<0.001$ \\
\hline $11-17$ & 0.19 & 0.10 to 0.39 & $<0.001$ \\
\hline $18-44$ & 0.52 & 0.44 to 0.62 & $<0.001$ \\
\hline $45-64$ & 0.61 & 0.54 to 0.69 & $<0.001$ \\
\hline $65-74$ & 0.77 & 0.68 to 0.87 & $<0.001$ \\
\hline $75-84$ & 1.00 & 1.00 & 1.00 \\
\hline$\geq 85$ & 1.12 & 1.00 to 1.26 & 0.05 \\
\hline Female sex & 1.28 & 1.18 to 1.40 & $<0.001$ \\
\hline \multicolumn{4}{|l|}{ Admission type } \\
\hline Medical & 2.30 & 2.01 to 2.64 & $<0.001$ \\
\hline Obstetrical & 0.04 & 0.015 to 0.091 & $<0.001$ \\
\hline Surgical & 1.00 & 1.00 & 1.00 \\
\hline Other & 2.52 & 1.29 to 4.92 & 0.007 \\
\hline Elective admission & 0.55 & 0.46 to 0.65 & $<0.001$ \\
\hline $\begin{array}{l}\text { Infection as most } \\
\text { responsible diagnosis }\end{array}$ & 0.90 & 0.78 to 1.02 & 0.10 \\
\hline \multicolumn{4}{|l|}{ Previous diagnoses } \\
\hline Myocardial infarction & 0.85 & 0.72 to 1.01 & 0.06 \\
\hline Congestive heart failure & 1.41 & 1.24 to 1.59 & $<0.001$ \\
\hline $\begin{array}{l}\text { Peripheral vascular } \\
\text { disease }\end{array}$ & 2.11 & 1.72 to 2.58 & $<0.001$ \\
\hline Cerebrovascular disease & 0.93 & 0.77 to 1.12 & 0.42 \\
\hline Dementia & 1.39 & 1.20 to 1.60 & $<0.001$ \\
\hline $\begin{array}{l}\text { Chronic obstructive } \\
\text { pulmonary disease }\end{array}$ & 1.17 & 1.03 to 1.33 & 0.014 \\
\hline $\begin{array}{l}\text { Rheumatological } \\
\text { disease }\end{array}$ & 1.55 & 1.10 to 2.18 & 0.012 \\
\hline Peptic ulcer disease & 2.05 & 1.57 to 2.68 & $<0.001$ \\
\hline Diabetes mellitus & 1.03 & 0.93 to 1.14 & 0.57 \\
\hline Hemiparesis/paraplegia & 2.04 & 1.49 to 2.79 & $<0.001$ \\
\hline Renal disease & 1.44 & 1.23 to 1.69 & $<0.001$ \\
\hline Malignancy & 1.18 & 1.03 to 1.35 & 0.020 \\
\hline Liver disease & 2.05 & 1.64 to 2.56 & $<0.001$ \\
\hline HIV & 1.56 & 0.50 to 4.91 & 0.45 \\
\hline $\begin{array}{l}\text { Inflammatory bowel } \\
\text { disease }\end{array}$ & 2.43 & 1.78 to 3.32 & $<0.001$ \\
\hline $\begin{array}{l}\text { Other } \\
\text { immunocompromise }\end{array}$ & 2.19 & 1.67 to 2.88 & $<0.001$ \\
\hline \multicolumn{4}{|c|}{ Healthcare exposure in preceding 8 weeks } \\
\hline Hospital admission & 1.64 & 1.31 to 2.05 & $<0.001$ \\
\hline $\begin{array}{l}\text { Emergency department } \\
\text { visit }\end{array}$ & 0.80 & 0.53 to 1.21 & 0.29 \\
\hline $\begin{array}{l}\text { Past gastrointestinal } \\
\text { procedure }\end{array}$ & 1.15 & 0.91 to 1.46 & 0.24 \\
\hline $\begin{array}{l}\text { Same-day surgery } \\
\text { procedure }\end{array}$ & 1.07 & 0.88 to 1.30 & 0.49 \\
\hline Nursing home stay & 1.08 & 0.73 to 1.60 & 0.71 \\
\hline Haemodialysis & 1.29 & 0.96 to 1.75 & 0.09 \\
\hline Chemotherapy & 0.89 & 0.68 to 1.15 & 0.37 \\
\hline Homecare treatment & 1.37 & 1.25 to 1.52 & $<0.001$ \\
\hline
\end{tabular}

Table 3 Continued

\begin{tabular}{|c|c|c|c|}
\hline & Adjusted OR & $95 \% \mathrm{Cl}$ & p Value \\
\hline $\begin{array}{l}\text { Recent diagnosis of } \\
\text { infection }\end{array}$ & 1.56 & 1.02 to 2.38 & 0.038 \\
\hline \multicolumn{4}{|c|}{ Calendar month of admission } \\
\hline January & 0.93 & 0.75 to 1.14 & 0.49 \\
\hline February & 1.03 & 0.84 to 1.26 & 0.80 \\
\hline March & 0.90 & 0.73 to 1.11 & 0.31 \\
\hline April & 1.08 & 0.90 to 1.29 & 0.42 \\
\hline May & 0.96 & 0.79 to 1.15 & 0.64 \\
\hline June & 1.03 & 0.85 to 1.24 & 0.78 \\
\hline July & 1.00 & 1.00 & 1.00 \\
\hline August & 1.06 & 0.87 to 1.29 & 0.59 \\
\hline September & 0.75 & 0.60 to 0.93 & 0.01 \\
\hline October & 0.90 & 0.73 to 1.11 & 0.32 \\
\hline November & 0.87 & 0.70 to 1.07 & 0.18 \\
\hline December & 0.85 & 0.69 to 1.06 & 0.15 \\
\hline \multicolumn{4}{|l|}{ Hospital characteristic } \\
\hline \multicolumn{4}{|l|}{ Hospital type } \\
\hline Academic/teaching & 2.13 & 1.55 to 2.93 & $<0.001$ \\
\hline Large community & 1.83 & 1.38 to 2.42 & $<0.001$ \\
\hline Medium community & 1.77 & 1.38 to 2.36 & $<0.001$ \\
\hline Small community & 1.00 & 1.00 & 1.00 \\
\hline \multicolumn{4}{|c|}{ Proportion of beds in single-bed rooms } \\
\hline$<25 \%$ & 1.00 & 1.00 & 1.00 \\
\hline $25 \%-35 \%$ & 1.16 & 0.86 to 1.55 & 0.34 \\
\hline$>35 \%$ & 1.16 & 0.92 to 1.47 & 0.21 \\
\hline Not available & 1.13 & 0.82 to 1.55 & 0.45 \\
\hline $\begin{array}{l}\text { Baseline C. difficile rates } \\
\text { in fiscal year } 2007\end{array}$ & 1.02 & 1.01 to 1.03 & 0.010 \\
\hline \multicolumn{4}{|l|}{ Testing method for $C$. difficile } \\
\hline $\begin{array}{l}\text { Standard culture } \\
\text { followed by cytotoxin } \\
\text { assay }\end{array}$ & 0.90 & 0.66 to 1.22 & 0.49 \\
\hline$P C R$ & 1.40 & 1.03 to 1.91 & 0.03 \\
\hline $\begin{array}{l}\text { Toxin A/B testing by } \\
\text { commercial enzyme } \\
\text { assay }\end{array}$ & 0.92 & 0.66 to 1.30 & 0.65 \\
\hline Other & 1.00 & 1.00 & 1.00 \\
\hline \multicolumn{4}{|l|}{ Hospital processes of care } \\
\hline $\begin{array}{l}\text { Immediate isolation for } \\
\text { patients with diarrhoea }\end{array}$ & 0.93 & 0.66 to 1.22 & 0.56 \\
\hline $\begin{array}{l}\text { Audit of compliance for } \\
\text { antibiotic stewardship }\end{array}$ & 1.17 & 0.92 to 1.50 & 0.20 \\
\hline $\begin{array}{l}\text { Audit of compliance of } \\
\text { environmental cleaning }\end{array}$ & 1.29 & 0.99 to 1.67 & 0.06 \\
\hline $\begin{array}{l}\text { Reporting to CEO or } \\
\text { hospital board }\end{array}$ & 0.97 & 0.77 to 1.21 & 0.78 \\
\hline $\begin{array}{l}\text { On-site } C . \text { difficile } \\
\text { diagnostic testing }\end{array}$ & 0.87 & 0.68 to 1.10 & 0.24 \\
\hline $\begin{array}{l}\text { Use of vancomycin as } \\
\text { first-line treatment }\end{array}$ & 1.19 & 0.87 to 1.63 & 0.28 \\
\hline
\end{tabular}

cleaning and decontaminating their micro-environment to prevent transmission to other hospitalised patients. Yet, emerging research, including whole genome sequencing studies, now suggests that symptomatic patients may 
be responsible for only a minority of new C. difficile transmissions. ${ }^{34} 35$ Asymptomatic colonised patients are not targeted by current prevention strategies and may represent another major reservoir of C. difficile infection. ${ }^{36} 37$ Still, other transmission events may be occurring in the community through mechanisms that are not yet well understood. ${ }^{38}$ Our data also suggest that patientlevel risk factors may be more important than hospitallevel processes in driving patient-level risk of infection. If current prevention efforts have limited yield in preventing C. difficile, this would call into question the fairness of hospital rankings, which use C. difficile rates as a quality indicator, and on funding withdrawal for admissions complicated by this infection.

\section{CONCLUSIONS}

In summary, our population-wide study has confirmed the importance of patient-level risk factors, such as age, comorbidity and admission type, in predicting a patient's risk of $C$. difficile infection. However, a range of selected understudied hospital-level prevention strategies appears to have either limited effectiveness or were ineffectively implemented at the time of this study. Given the limitations of an observational study design and the fact that we could not study well-established prevention measures that were already instituted in all hospitals, we would not recommend withdrawing these processes or diverting resources away from C. difficile infection prevention programmes. However, our findings do suggest the need to improve implementation of C. difficile prevention practices, assess the system-wide benefits of putative prevention processes and to uncover other innovative means of $C$. difficile prevention.

\footnotetext{
Author affiliations

${ }^{1}$ Institute for Clinical Evaluative Sciences, Toronto, Ontario, Canada

${ }^{2}$ Division of Infectious Diseases, Department of Medicine, Sunnybrook Health Sciences Centre, University of Toronto, Toronto, Ontario, Canada

${ }^{3}$ Institute of Health Policy, Management and Evaluation,

University of Toronto, Toronto, Ontario, Canada

${ }^{4}$ Division of Paediatric Medicine, Hospital for Sick Children,

Toronto, Ontario, Canada

${ }^{5}$ Department of Paediatrics, University of Toronto, Toronto, Ontario, Canada

${ }^{6}$ Health Analytics Branch, Ontario Ministry of Health and Long-Term Care, Toronto, Ontario, Canada

Twitter Follow Debbie Gibson at @debbieandrockie

Contributors ND, AG and TAS conceived the research question. $\mathrm{ND}, \mathrm{AG}, \mathrm{XM}, \mathrm{DG}, \mathrm{XW}$ and TAS were all involved in study design, data acquisition, analysis and interpretation. All authors were involved in drafting the manuscript, revising it for important intellectual content, gave approval for publication and agree to be accountable for all aspects of the work.
}

Funding This work was supported by an Ontario Ministry of Health and Long-Term Care (MOHLTC) Academic Health Sciences Centre Alternate Funding Plan Innovation Fund Award. ND is supported by a CIHR Clinician Scientist Award. AG is supported by a Canadian Institutes of Health Research (CIHR) Applied Chair in Child Health Services and Policy Research. This study was conducted at the Institute for Clinical Evaluative Sciences (ICES), which is funded by an annual grant from the Ontario MOHLTC. The opinions, results and conclusions reported in this paper are those of the authors and are independent from the funding sources. No endorsement by ICES or the Ontario MOHLTC is intended or should be inferred.

Competing interests None declared.

Ethics approval Sunnybrook Health Sciences Centre Research Ethics Board.

Provenance and peer review Not commissioned; externally peer reviewed.

Data sharing statement The de-identified population-wide data are housed at the Institute for Clinical Evaluative Sciences with strict privacy safeguards.

Open Access This is an Open Access article distributed in accordance with the Creative Commons Attribution Non Commercial (CC BY-NC 4.0) license, which permits others to distribute, remix, adapt, build upon this work noncommercially, and license their derivative works on different terms, provided the original work is properly cited and the use is non-commercial. See: http://creativecommons.org/licenses/by$\mathrm{nc} / 4.0 /$

\section{REFERENCES}

1 Kwong JC, Ratnasingham S, Campitelli MA, et al. The impact of infection on population health: results of the Ontario burden of infectious diseases study. PLoS One 2012;7:e44103.

2 Magill SS, Edwards JR, Bamberg W, et al. Multistate point-prevalence survey of health care-associated infections. N Engl J Med 2014;370:1198-208.

3 Daneman N, Stukel TA, Ma X, et al. Reduction in Clostridium difficile infection rates after mandatory hospital public reporting: findings from a longitudinal cohort study in Canada. PLoS Med 2012;9:e1001268.

4 Fung CH, Lim YW, Mattke S, et al. Systematic review: the evidence that publishing patient care performance data improves quality of care. Ann Intern Med 2008;148:111-23.

5 Lee GM, Kleinman K, Soumerai SB, et al. Effect of nonpayment for preventable infections in U.S. hospitals. N Engl J Med 2012;367:1428-37.

6 Juurlink DN, Mamdani MM, Lee DS, et al. Rates of hyperkalemia after publication of the Randomized Aldactone Evaluation Study. N Engl J Med 2004;351:543-51.

7 Tu JV, Bowen J, Chiu M, et al. Effectiveness and safety of drug-eluting stents in Ontario. N Engl J Med 2007;357:1393-402.

8 Stukel TA, Schull MJ, Guttmann A, et al. Health impact of hospital restrictions on seriously ill hospitalized patients: lessons from the Toronto SARS outbreak. Med Care 2008;46:991-7.

9 Lowe DO, Mamdani MM, Kopp A, et al. Proton pump inhibitors and hospitalization for Clostridium difficile-associated disease: a population-based study. Clin Infect Dis 2006;43:1272-6.

10 Guttmann A, Zagorski B, Austin PC, et al. Effectiveness of emergency department asthma management strategies on return visits in children: a population-based study. Pediatrics 2007;120:e1402-10.

11 Daneman N, Gruneir A, Bronskill SE, et al. Prolonged antibiotic treatment in long-term care: role of the prescriber. JAMA Intern Med 2013;173:673-82.

12 Glazier RH, Klein-Geltink J, Kopp A, et al. Capitation and enhanced fee-for-service models for primary care reform: a population-based evaluation. CMAJ 2009;180:E72-81.

13 Scheurer DB, Hicks LS, Cook EF, et al. Accuracy of ICD-9 coding for Clostridium difficile infections: a retrospective cohort. Epidemiol Infect 2007;135:1010-13. 
14 Dubberke ER, Reske KA, McDonald LC, et al. ICD-9 codes and surveillance for Clostridium difficile-associated disease. Emerg Infect Dis 2006;12:1576-9.

15 Brown KA, Daneman N, Arora P, et al. The co-seasonality of pneumonia and influenza with Clostridium difficile infection in the United States, 1993-2008. Am J Epidemiol 2013;178:118-25.

16 Kutty PK, Woods CW, Sena AC, et al. Risk factors for and estimated incidence of community-associated Clostridium difficile infection, North Carolina, USA. Emerg Infect Dis 2010;16:197-204.

17 Gravel D, Gardam M, Taylor G, et al. Infection control practices related to Clostridium difficile infection in acute care hospitals in Canada. Am J Infect Control 2009;37:9-14.

18 Hamel M, Zoutman D, O'Callaghan C. Exposure to hospital roommates as a risk factor for health care-associated infection. Am J Infect Control 2010;38:173-81.

19 Moehring RW, Lofgren ET, Anderson DJ. Impact of change to molecular testing for Clostridium difficile infection on healthcare facility-associated incidence rates. Infect Control Hosp Epidemiol 2013;34:1055-61.

20 Zar FA, Bakkanagari SR, Moorthi KM, et al. A comparison of vancomycin and metronidazole for the treatment of Clostridium difficile-associated diarrhea, stratified by disease severity. Clin Infect Dis 2007;45:302-7.

21 Cao J, Zhang S. Multiple comparison procedures. JAMA 2014;312:543-4.

22 Ali M, Ananthakrishnan AN, Ahmad S, et al. Clostridium difficile infection in hospitalized liver transplant patients: a nationwide analysis. Liver Transpl 2012;18:972-8.

23 McFarland LV, Surawicz CM, Stamm WE. Risk factors for Clostridium difficile carriage and C. difficile-associated diarrhea in a cohort of hospitalized patients. J Infect Dis 1990;162:678-84.

24 Bignardi GE. Risk factors for Clostridium difficile infection. J Hosp Infect 1998;40:1-15.

25 Kyne L, Sougioultzis S, McFarland LV, et al. Underlying disease severity as a major risk factor for nosocomial Clostridium difficile diarrhea. Infect Control Hosp Epidemiol 2002;23:653-9.

26 Vesta KS, Wells PG, Gentry CA, et al. Specific risk factors for Clostridium difficile-associated diarrhea: a prospective, multicenter, case control evaluation. Am J Infect Control 2005;33:469-72.
27 Dubberke ER, Yan Y, Reske KA, et al. Development and validation of a Clostridium difficile infection risk prediction model. Infect Control Hosp Epidemiol 2011;32:360-6.

28 Claesson MJ, Jeffery IB, Conde S, et al. Gut microbiota composition correlates with diet and health in the elderly. Nature 2012;488:178-84.

29 Dubberke ER, Gerding DN, Classen D, et al. Strategies to prevent Clostridium difficile infections in acute care hospitals. Infect Control Hosp Epidemiol 2008;29(Suppl 1): S81-92.

30 Gilca R, Hubert B, Fortin E, et al. Epidemiological patterns and hospital characteristics associated with increased incidence of Clostridium difficile infection in Quebec, Canada, 1998-2006. Infect Control Hosp Epidemiol 2010;31:939-47.

31 van der Kooi TI, Koningstein M, Lindemans A, et al. Antibiotic use and other risk factors at hospital level for outbreaks with Clostridium difficile PCR ribotype 027. J Med Microbiol 2008;57(Pt 6):709-16.

32 Feazel LM, Malhotra A, Perencevich EN, et al. Effect of antibiotic stewardship programmes on Clostridium difficile incidence: a systematic review and meta-analysis. J Antimicrob Chemother 2014;69:1748-54.

33 McGeer A. Ontario Antimicrobial Stewardship Project: Survey Report. Institute for Safe Medication Practices (ISMP), Canada, 2009.

34 Walker AS, Eyre DW, Wyllie DH, et al. Characterisation of Clostridium difficile hospital ward-based transmission using extensive epidemiological data and molecular typing. PLoS Med 2012;9:e1001172.

35 Eyre DW, Cule ML, Wilson DJ, et al. Diverse sources of C. difficile infection identified on whole-genome sequencing. N Engl J Med 2013;369:1195-205.

36 Samore MH, DeGirolami PC, Tlucko A, et al. Clostridium difficile colonization and diarrhea at a tertiary care hospital. Clin Infect Dis 1994;18:181-7.

37 Loo VG, Bourgault AM, Poirier L, et al. Host and pathogen factors for Clostridium difficile infection and colonization. N Engl J Med 2011;365:1693-703.

38 Chitnis AS, Holzbauer SM, Belflower RM, et al. Epidemiology of community-associated Clostridium difficile infection, 2009 through 2011. JAMA Intern Med 2013;173:1359-67. 